\title{
On the hot pressing of coloured high-gold alloys powder compacts applied to the manufacturing of innovative jewellery items
}

\author{
B. Henriques $\cdot$ P. Pinto $\cdot$ J. Souza $\cdot$ J. C. Teixeira $\cdot$ D. Soares $\cdot$ F. S. Silva
}

Published online: 19 April 2013

C The Author(s) 2013. This article is published with open access at SpringerLink.com

\begin{abstract}
Innovative design through colour has always been a very important feature in decorative items, jewellery inclusive. The use of coloured gold alloys (e.g. red, white, green) in the manufacture of jewellery artifacts is nowadays generalized, and one can often see jewellery items that combine more than a single colour. However, multicoloured jewellery artifacts are generally made of parts produced separately and bonded together in a later step. The ability to produce jewellery sub-components or final pieces using a powder metallurgy process aimed at producing innovative multi-coloured gold jewellery items with colour gradients is explored in this paper. Four $19.2 \mathrm{ct}$ coloured gold powders (yellow, green, red and white) were hot pressed at different times and temperatures and the resulting samples were analyzed in terms of their microstructure, hardness, porosity, microstructure and optical properties. A manufacturing route to obtain multi-coloured jewellery pieces with colour gradients is also presented.
\end{abstract}

Keywords Gold alloys · Powder metallurgy · Hot pressing · Optical properties $\cdot$ Microstructure $\cdot$ Hardness

\section{Introduction}

Gold and gold alloys have been for ages the metal of choice for jewellery manufacturing. The jewellery items are classified in terms of gold content, described in terms of caratage, and a range of caratages are used depending on the country in which the jewellery items are traded. High caratages (24,

B. Henriques $(\bowtie) \cdot$ P. Pinto $\cdot$ J. Souza $\cdot$ J. C. Teixeira $\cdot$ D. Soares $\cdot$

F. S. Silva

Center for Mechanical and Materials Technologies,

Universidade do Minho, Campus de Azurém,

4800-058 Guimarães, Portugal

e-mail: brunohenriques@dem.uminho.pt
22 and $21 \mathrm{ct}$ ) are mostly traded in Asian countries whereas lower caratages $(18,14,9 \mathrm{ct})$ are mostly found in western countries [1]. Nevertheless, there are some exceptions to this rule and Portugal is one of them. The standard caratage in Portugal is $19.2 \mathrm{ct}$ ( 800 fineness), although sale of other caratages is now allowed.

Coloured gold is an aesthetic feature that has been used by jewellery makers and designers in the creative process in order to make jewellery more appealing to customers. Gold and copper are the only two pure metals with intrinsic colour, all other pure metals being white or grey. Moreover, gold alloys can be produced in several colours depending on the alloying elements that are added. The conventional carat gold colours often used in jewellery making are yellow, green and red, and they are all based in the $\mathrm{Au}-\mathrm{Ag}-\mathrm{Cu}$ ternary system. White carat golds have also been used since 1920s when there was a need for platinum substitution. There are two main types of white golds: the nickel whites and palladium whites [2]. Both nickel and palladium have a strong bleaching effect in gold. Gold can assume almost any colour in the visible spectrum but most of the unusual coloured alloys lack ductility and toughness, and cannot undergo considerable plastic deformation, which make them inappropriate for the production of jewellery. Blue and purple golds are two good examples of fragile coloured golds, which are formed by intermetallic compounds. Its application has been shown possible after being faceted and used as gemstones and inlays [3]. More recently, Fischer-Bühner et al. [4] and Klotz [5] have shown some improvements in the production of plated and cast blue and purple golds.

Innovative design plays a determinant role in a fastchanging industry that the jewellery industry is [6]. The demand for up-to-date jewellery items in shorter time frames has put the production technology in the centre of the jewellery business, as a key element of competitiveness. 
The introduction of non-conventional technologies such as lasers, $\mathrm{CAD} / \mathrm{CAD}$ systems, electroforming and powder metallurgy $(\mathrm{P} / \mathrm{M})$ in the production of jewellery are just a few examples of the technological tools available today in the jewellery industry [7]. This work intends to demonstrate $\mathrm{P} / \mathrm{M}$ as a technological tool to create innovative jewellery items. $\mathrm{P} / \mathrm{M}$ has been presented on several occasions and discussed at jewellery forums, such as the Santa $\mathrm{Fe}$ Symposium [8-12] and World Gold Council Technical Conferences $[13,14]$. The $\mathrm{P} / \mathrm{M}$ technique has also been shown to be cost effective in the production of carat gold wedding rings, in which their mechanical properties compared favorably with those produced by lost wax casting technique [9]. The production of products which combine several colours can be accomplished by this technique, either in a random way as demonstrated by Taylor [15], or in a continuous transition in colour, as proposed by Böhm [7]. The multi-coloured products thus produced have the advantage over any coloured coatings of being permanent, i.e. the aesthetic feature results in the bulk material and it cannot be removed by any erosive agent, thus lasting for the piece's lifetime.

The present work is devoted to the study of the hot pressing conditions of several coloured $19.2 \mathrm{ct}$ gold alloys and the influence of processing conditions on the microstructure, hardness and optical properties of the hot pressed samples. The aim was to determine the appropriate processing conditions for the production of innovative jewellery pieces using a $\mathrm{P} / \mathrm{M}$ process. Several examples of products thus obtained are disclosed in the last section of the paper.

\section{Material and methods}

\section{Powders}

In this study, four different 19.2 ct gold alloys were used in the form of metal powders. Table 1 shows the chemical composition of the alloys obtained by energy-dispersive X-ray spectroscopy (Nova 200, FEI, Oregon, USA). Powders were obtained by a process of solid-state reduction by the means of in-house equipment that uses a file to

Table 1 Chemical composition of 19.2 ct coloured gold alloys

\begin{tabular}{lllllll}
\hline Alloy & Colour & $\mathrm{Au}$ & $\mathrm{Cu}$ & $\mathrm{Ag}$ & $\mathrm{Ni}$ & $\mathrm{Zn}$ \\
\hline A & Yellow & $80(79)$ & $10(11)$ & 10 & & \\
B & Green & $80(81)$ & & $20(19)$ & & \\
C & Red & $80(81)$ & $(20) 19$ & & & \\
D & White & $80(76)$ & $10(12)$ & & $5(7)$ & $5(5)$ \\
\hline
\end{tabular}

Numbers in brackets indicate the composition, in wt.\%, of the alloys measured by EDS analysis produce powders on a small scale. At this point, it is important to state that no significant iron traces were found in the EDS analysis of powders. The morphology of the irregularshaped powders thus produced is presented in Fig. 1. Powders can be spherical or irregular in geometry. Air atomized powders are spherical while water atomized powders or those obtained from a filing process are irregular. The morphology of powders can have a strong influence on the mechanical strength of pre compacted powder compacts, also called green compacts. Fine and irregular powders are preferred to coarse and spherical powders due to higher contact points between particles and higher ability for mechanical interlocking to occur. In this study, despite powders having an irregular shape, which might have resulted in higher green strength, the powders were not subjected to pre-compaction for shaping before the hot pressing process. As will be presented ahead in this paper, they rather underwent a hot compaction inside the graphite die during the initial stage of the hot pressing process. High temperatures make powders softer and easy to densify. Therefore, in this case as well as in other similar situations, the shape of the powders did not assume a critical role. Less geometric and size specifications of powders processed by hot pressing may result in relevant cost savings in the manufacturing process.

The size distribution of powders was determined by the means of a laser particle size analyzer (Malvern HSD2600, Malvern Instruments Ltd, England). The particle size distribution of powders is shown in Table 2 .

\section{Processing conditions}

Several gold coloured specimens were obtained by the hot pressing $\mathrm{P} / \mathrm{M}$ technique. Powders were hot pressed under a range of selected conditions of pressure, time and temperature, which are shown in Table 3 . Hot pressing was performed

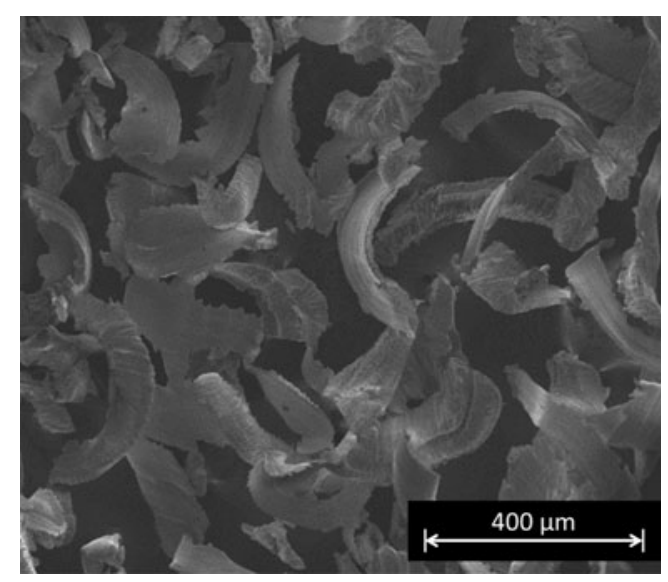

Fig. 1 SEM micrograph showing the morphology of the 19.2 ct gold alloy powders $(\times 250)$ 
Table 2 Powders size distribution of several 19.2 ct coloured gold alloys [in micrometer]

\begin{tabular}{lllll}
\hline Alloy & Colour & $d_{10}$ & $d_{50}$ & $d_{90}$ \\
\hline A & Yellow & 64 & 158 & 223 \\
B & Green & 66 & 161 & 224 \\
C & Red & 53 & 129 & 219 \\
D & White & 50 & 114 & 209 \\
\hline
\end{tabular}

$d_{10}, d_{50}, d_{90}$ particle size values indicating that, respectively, 10,50 and $90 \%$ of the distribution is below this value, i.e. a $d_{10}$ of $64 \mu \mathrm{m}$ means $10 \%$ of the sample is below $64 \mu \mathrm{m}$ in size (using a volume-based calculation)

under vacuum ( $10^{-2}$ mbar) using in-house equipment (Fig. 2) based on a vacuum chamber and an induction heating furnace (Ameritherm Easyheat 5060). The die was made of graphite and had a cavity with $4 \mathrm{~mm}$ diameter. Specimens had therefore the diameter $(4 \mathrm{~mm})$ and also $4 \mathrm{~mm}$ height.

\section{Microstructure and chemical analysis}

The hot pressed compacts were analyzed by optical microscopy (Axiotech, Carl Zeiss, USA) and SEM/EDS (Nova 200, FEI, Oregon, USA). For that, all samples were embedded in cold-curing-type epoxy resin and subjected to the wet grinding process. The samples were first ground on $\mathrm{SiC}$ paper down to a 1200-grit finish and then successively polished using a polishing cloth filled with diamond suspension with 6 and $1 \mu \mathrm{m}$ particles. Then, all specimens were ultrasonically cleaned in an alcohol bath for $10 \mathrm{~min}$ and rinsed in distilled water for another $10 \mathrm{~min}$ to remove contaminants. Afterwards, they were dried with adsorbent paper towels.

The microstructures of hot pressed specimens were examined after etching the surface with a solution based on $100 \mathrm{~g}$ hydrochloric acid $+3 \mathrm{~g}$ chromic acid.

\section{Porosity measurement}

The porosity existing in the hot pressed powder compacts was measured by the means of image analysis (ImageJ). The porosity of each specimen was calculated as an average of six measurements at random locations on the specimen's surface. Prior to image analysis, all specimens had undergone a further polishing cycle down to a mirror finish state, followed by another cleaning step.

Table 3 Hot pressing conditions of the gold alloy powders

\begin{tabular}{lcc}
\hline $\begin{array}{l}\text { Pressure } \\
(\mathrm{MPa})\end{array}$ & $\begin{array}{l}\text { Time } \\
(\mathrm{min})\end{array}$ & Temperature $\left({ }^{\circ} \mathrm{C}\right)$ \\
\hline 35 & 10 & 700 \\
& 30 & 800 \\
& 60 & \\
\hline
\end{tabular}

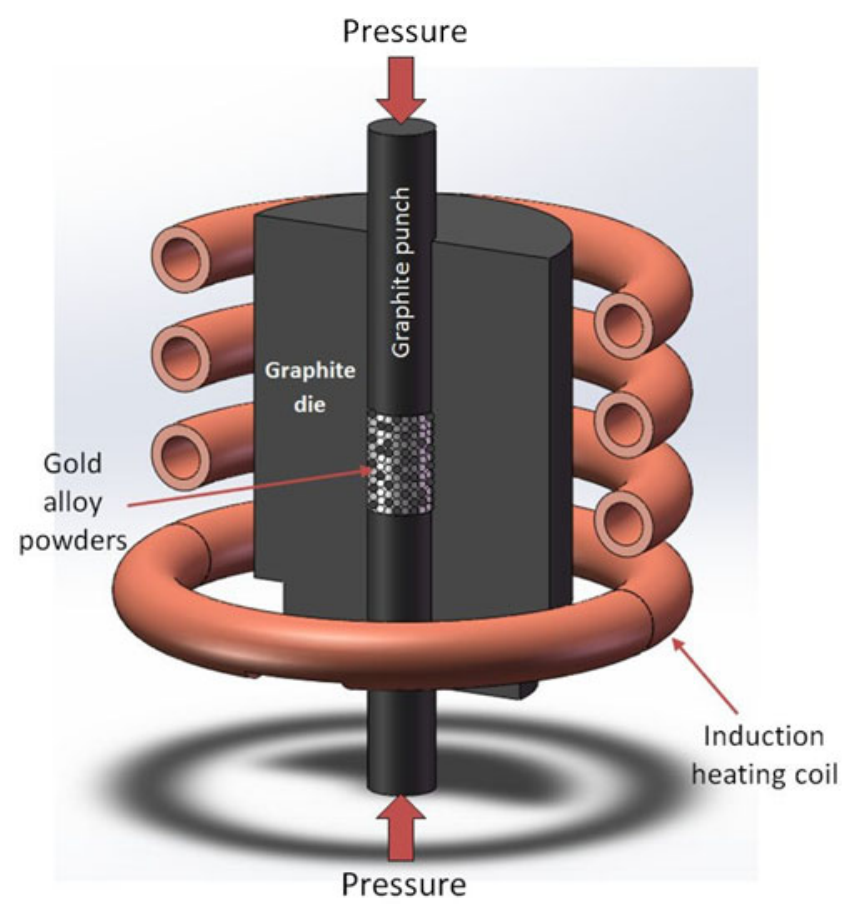

Fig. 2 The hot pressing process: schematic of the apparatus

\section{Hardness measurement}

The Vickers hardness evaluation (microhardness tester, type M, Shimadzu, Japan) of the hot pressed compacts was performed for all specimens. Five indentations were made in each specimen and the mean value and standard deviation were calculated. The load used was $1,000 \mathrm{~g}$ during $15 \mathrm{~s}$.

\section{Spectrophotometric colourimetry}

Colour measurement of the samples was performed in a computer-controlled spectrophotometer (Shimadzu UV-2450, Shimadzu Corporation, Kyoto, Japan). Spectral reflectance data from the mirror-polished flat surface were recorded at $1 \mathrm{~nm}$ wavelength intervals from 380 to $780 \mathrm{~nm}$ with the geometry of diffuse illumination and $10^{\circ}$ viewing. The three-dimensional colour coordinates using the CIELab system, $L^{*}$ (lightness), $a^{*}$ (red-green chromaticity index) and $b^{*}$ (yellow-blue chromaticity index), were obtained. The exposed area of the hot pressed specimens for colour measurement was $7 \mathrm{~mm}^{2}$.

\section{Results and discussion}

\section{Microstructure}

The microstructures of the hot pressed gold coloured samples are shown in Fig. 3. They all exhibited similar microstructures, regardless of the hot pressing time and temperature. Similar grain sizes were found among the different alloys 

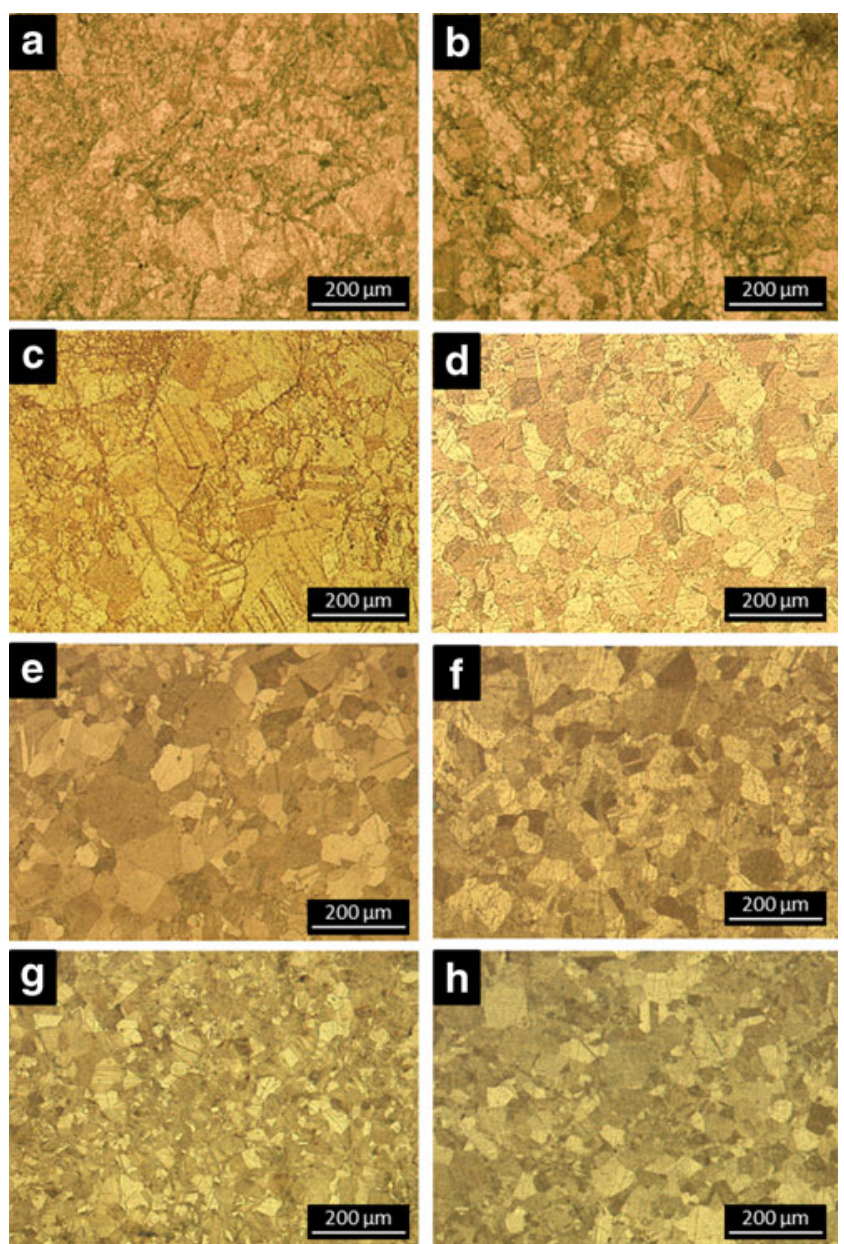

Fig. 3 Microstructures of 19.2 ct coloured gold alloys hot pressed for $30 \mathrm{~min}$ at the temperatures of 700 and $800^{\circ} \mathrm{C}$ : a green gold, $700^{\circ} \mathrm{C}$; b green gold, $800{ }^{\circ} \mathrm{C}$; c yellow gold, $700{ }^{\circ} \mathrm{C}$; d yellow gold, $800{ }^{\circ} \mathrm{C}$; $\mathbf{e}$ red gold, $700{ }^{\circ} \mathrm{C}$; f red gold, $800{ }^{\circ} \mathrm{C}$; $\mathbf{g}$ white gold, $700{ }^{\circ} \mathrm{C}$; h white gold, $800{ }^{\circ} \mathrm{C}(\times 200)$

and no significant grain growth could be observed for higher temperatures $\left(800^{\circ} \mathrm{C}\right)$ and longer hot pressing times $(60 \mathrm{~min})$. The similarity to the grain size of the hot pressed coloured samples contrasted with the different grain structures of the ascast bulk alloys, where the green gold (alloy A) exhibited the finest grains and the red gold (alloy $\mathrm{C}$ ) exhibited the coarser grains. It has been demonstrated that a fine-grain structure is preferred to a coarse grain one, as it positively impacts the mechanical properties, such as tensile strength and elongation [16]. The surfaces of fine-grained gold alloys have also been reported to be more easily polished [17]. However, fine-grain structures in gold alloys (as also in copper alloy castings) do not seem to improve other properties like the hardness and yield strength $[16,18]$, at least in the practical range of grain refinements commonly used in the jewellery manufacturing. The grains size of the gold hot pressed samples shown in Fig. 3 is below $100 \mu \mathrm{m}$, which is regarded as fine grains in precious metals technology standards [16].
No dendritic segregations were found among the hot pressed samples, contrary to what is often found in cast samples [19]. The microstructures of all samples also revealed the presence of twins within the grains, which are often found in gold-silver-copper alloys. The appearance of twins as well as the lack of as-cast dendritic structure might be synonym of recrystallization having occurred, hence lack of segregation seen. This might also indicate that recrystallization is dynamic during hot pressing (hot working).

\section{Porosity}

Figure 4 shows the porosity measured in the samples for the different alloys and processing conditions. The porosity is lower than $0.5 \%$, except for the case of alloy A (green gold) that showed higher porosity $(\sim 0.9 \%)$ for the hot pressing condition of $700{ }^{\circ} \mathrm{C}, 10 \mathrm{~min}$. Results showed that no significant difference could be observed in the porosity level of the hot pressed samples, regardless the processing conditions used in this study. This means that at these temperature levels, the sintering time did not substantially impact the porosity of the compacts. On the other hand, it can significantly influence other mechanical properties of the samples, such as tensile and rupture strength, but that issue was not assessed in this study. The hot pressing technique is known for producing fully dense parts [20-26] and the results reflect well this feature of the process.

\section{Hardness}

Hardness is perhaps the most important property among the mechanical properties that can be assessed in an alloy for jewellery making: first, because it is easy to measure and, second, because it greatly impacts the fabrication and the performance of the jewellery item when worn by the customer [27].

The hardness data of hot pressed samples obtained in different conditions are shown in Fig. 5. The data shows that the hardness values are not significantly changed with the different processing conditions within each type of gold alloy. These results may be related with the results exhibited in Fig. 4 that show that all specimens are fully dense $(d>99 \%)$, regardless the processing condition. Also, at such high hot pressing temperatures $\left(700\right.$ and $\left.800{ }^{\circ} \mathrm{C}\right)$ these alloys, all containing $\mathrm{Cu}$, do not develop any age hardening mechanism. The main hardening mechanisms are therefore the solid solution and the ordering of the $\mathrm{Cu}$-rich phase, which accounts for the different hardness of the alloys.

Age hardening occurs either in high or low carat alloys during the annealing of the alloy at moderate temperatures, ranging from 300 to $500{ }^{\circ} \mathrm{C}$, which causes the formation of two phases, silver- and copper-rich solid solutions [28]. The hardening of the alloy is due to the formation of these two 

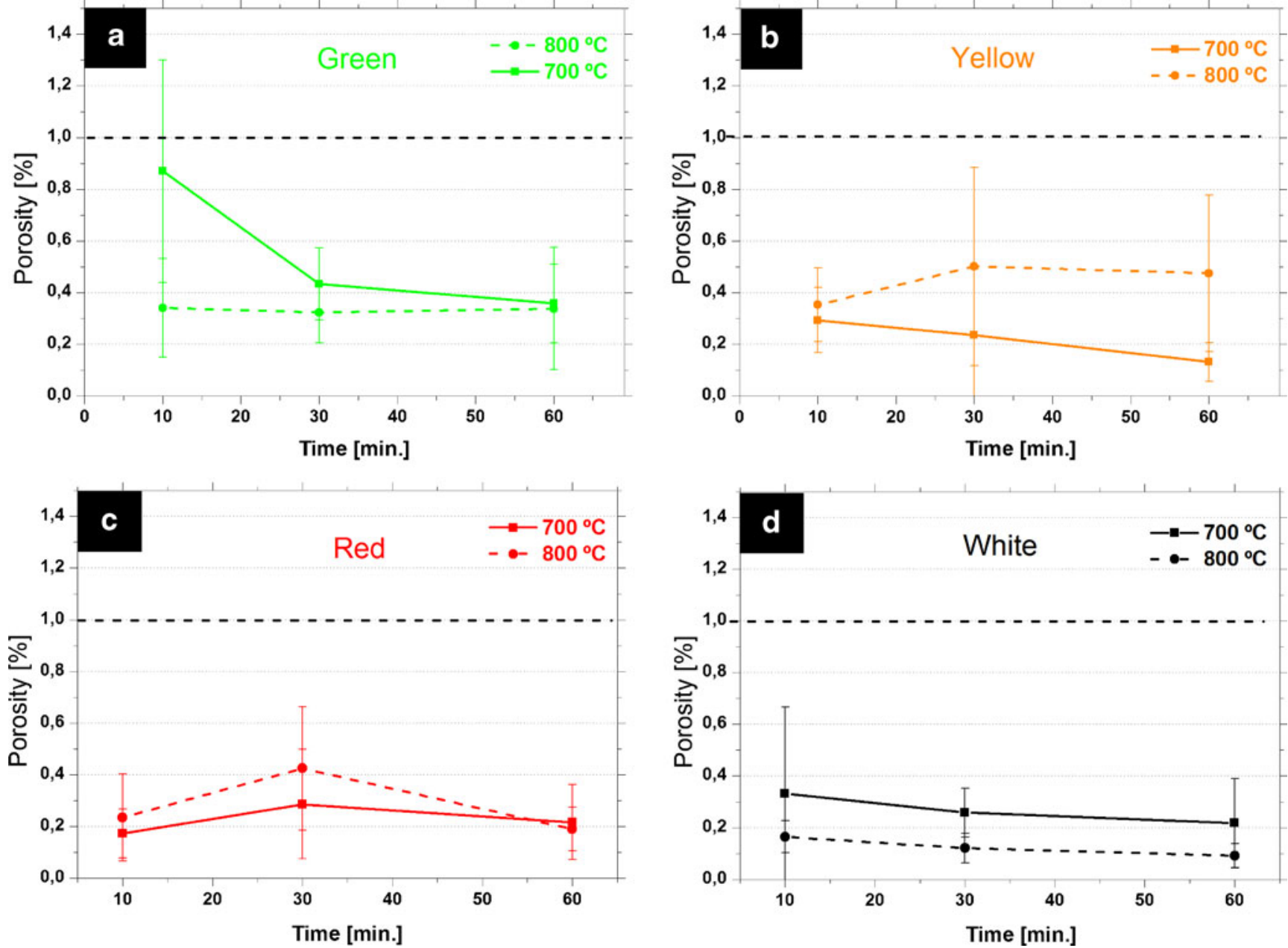

Fig. 4 Influence of the processing parameters (time and temperature) on the porosity of the hot pressed $19.2 \mathrm{ct}$ gold samples of different chemical compositions

phases, the silver- and the copper-rich solid solutions, where the precipitation of the latter phase accounts for the hardening

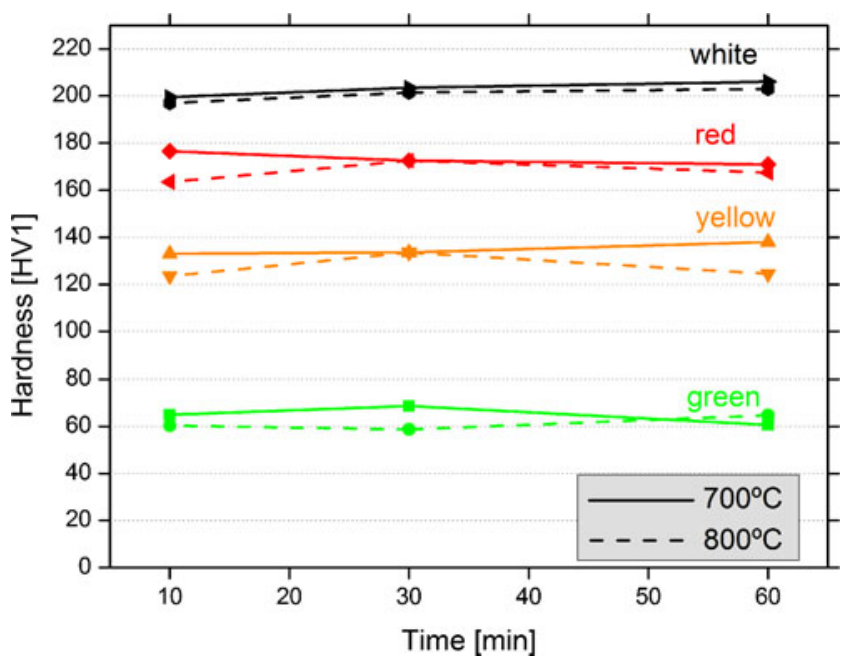

Fig. 5 Influence of the processing parameters (time and temperature) on the hardness of the hot pressed 19.2 ct coloured gold alloy powder compacts of the alloy. Age hardening in copper-containing alloys is also due to ordering reaction (order/disorder). It is important to point out that in the present study the samples were annealed at 700 and $800{ }^{\circ} \mathrm{C}$ (during the hot pressing process with duration of 10, 30 and $60 \mathrm{~min}$ ) and not age hardened.

The alloys A (green gold), B (yellow gold) and C (red gold) are based on the ternary $\mathrm{Au}-\mathrm{Ag}-\mathrm{Cu}$ systems and they consequently follow the typical properties of these alloys. In this system, the strength and hardness of the alloy increases with increasing content of copper [28]. The strengthening and hardening mechanisms caused by the silver and copper addition to gold is called solid solution strengthening. However, due to copper's smaller atoms size and higher shear modulus relative to silver ones, its substitution in the gold crystal lattice results in a greater hardening effect. Hence, alloy A (green gold), which contain no copper, exhibited the least hardness, 61-69 HV. The alloy B (yellow gold), containing $10 \mathrm{wt} . \%$ copper, presented higher hardness (124-138 HV). Finally, alloy C, which contained 20 wt.\% copper displayed the highest hardness among the alloys 
based in the $\mathrm{Au}-\mathrm{Ag}-\mathrm{Cu}$ system, between 165 and $176 \mathrm{HV}$. The alloy D (white gold) is a nickel-white gold and presented the highest hardness among the alloys tested (197-206 HV). Nickel is added to gold to provide it with a white colour along with increased strength and hardness [2].

\section{Spectrophotometric colourimetry}

Figure 6 shows a 3D plot comprising the three colour coordinates of the CIELab system $\left(L^{*}, a^{*}\right.$ and $\left.b^{*}\right)$, measured for the hot pressed coloured gold samples processed in different conditions (Table 3 ). The $L^{*}$ coordinate expresses the luminance (brightness) and it can vary between 0 , where no light is reflected by the sample, and 100, meaning that all incident light is reflected. The $L^{*}$ value registered for the different samples did not significantly differ within each group, ranging from $\sim 55$ to $\sim 59$. These luminance values are relatively lower than those reported by Shirishi et al. [29], but such differences are related to colour measuring experimental set up, particularly with the reduced area of the samples that was used for measuring the colour.

The $a^{*}$ coordinate measures the intensity of the green (negative) or red (positive) component of the spectrum, whereas $b^{*}$ measures the blue (negative) or yellow (positive) component part. Figure 6 shows a significant variation in $a^{*}$ and $b^{*}$ coordinates between the four type of alloys $\mathrm{A}-\mathrm{D}$ but no significant changes within the same group of specimens. Thus, the alloy A exhibited a low values for $a^{*}$ coordinate, from 0.46 to 2.39 , and higher $b^{*}$ coordinates (20.9 to 23.1), which reveal a strong intensity of the green colour. The alloy
B exhibited higher values for $a^{*}$ coordinates (4.4 to 5.5) and lower $b^{*}$ coordinates $(17.2$ to 19.2$)$ relative to alloy $\mathrm{A}$, which resulted in the measurement of an intense yellow component coupled with a moderate component of red, thus providing to this alloy a reddish yellow colour. The alloy $\mathrm{C}$ displayed the highest value for $a^{*}$ coordinate (6.5 to 7.2) and relatively low values for $b^{*}$ coordinate, which makes this alloy looks red. Finally, the alloy D exhibited low $a^{*}$ (2.3 to 2.7$)$ and $b^{*}(10.1$ to 11.8 ) coordinate values, which is typical of metals with white colour such as pure silver and pure platinum [29].

Figure 7 shows the reflectance curves for the hot pressed coloured gold samples, processed at $700{ }^{\circ} \mathrm{C}$ for $30 \mathrm{~min}$. The reflectance data obtained in this particular processing condition was considered to be representative of the global reflectance behaviour exhibited by the other specimens when processed under the other conditions. The spectral reflectance of the gold alloys used in this study revealed a general trend of higher reflectance for long wavelengths and lower reflectance for short wavelengths within the visible spectrum. Thus, the reflectance exhibited a decreasing trend from long wavelengths towards short wavelengths, with a higher decreasing slope being visible in the wavelengths interval comprised between 500 and $60 \mathrm{~nm}$ for alloys A, B and $\mathrm{C}$, but less pronounced in alloy $\mathrm{D}$.

The higher reflectance for high wavelengths exhibited by alloys A, B and C are in agreement with Shiraishi et al. [29] findings for gold alloys with high gold content. The same authors showed that the three pure elements composing these alloys, i.e. $\mathrm{Au}-\mathrm{Ag}-\mathrm{Cu}$, all exhibited the same reflectance pattern for high wavelengths. In contrast, at low wavelengths, the alloy A displayed lower reflectance than
Fig. 6 Colour comparison of the 19.2 ct coloured gold hot pressed samples plotted in the CIELab system

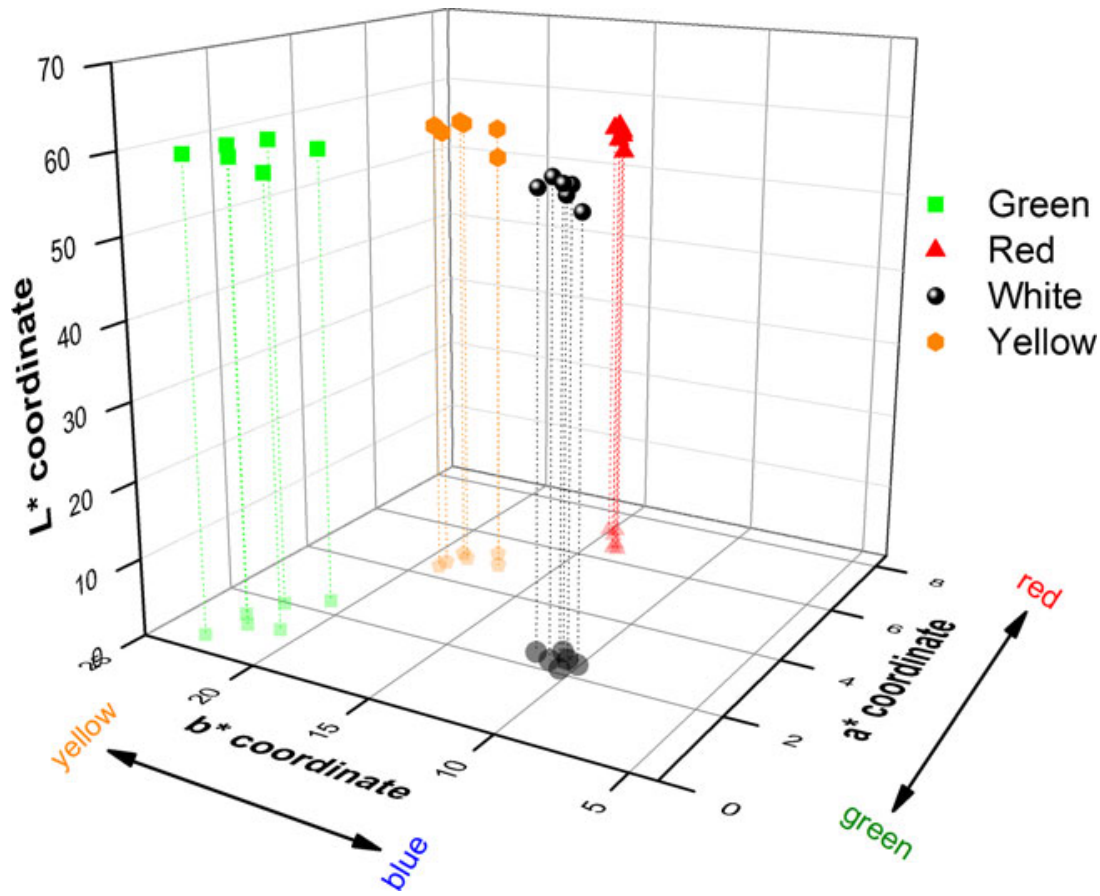




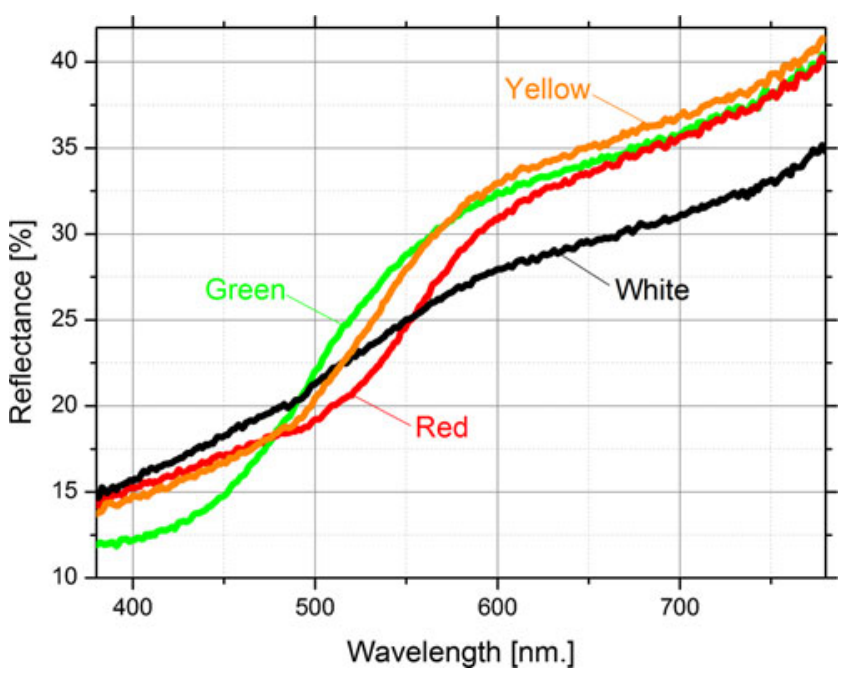

Fig. 7 Reflectance of hot pressed coloured gold alloys plotted against the wavelength in the region of the visible spectrum $(380-780 \mathrm{~nm})$

those of alloys B and C. The behaviour of alloy A is explained by the presence in the alloy of $20 \mathrm{wt} . \% \mathrm{of} \mathrm{Ag}$, as single alloying element. It was demonstrated by Shiraishi et al. [29] that, in Au-Ag alloys, the addition of Ag to pure $\mathrm{Au}$ up to a maximum content of $70 \mathrm{wt} . \%$, resulted in a reflectance drop for low wavelengths in comparison to that observed for pure gold.

The alloy D showed similar behaviour to alloys A, B and C, with low reflectance values for low wavelengths. Regarding high wavelengths, the reflectance was lower than that exhibited by the other alloys and the steep reflectance transition between low and high wavelengths could not be observed. The spectral reflectance curve of this alloy showed to be highly influenced by the presence of $\mathrm{Ni}$ as alloying element, once its behaviour is very similar to that exhibited by pure nickel [30].

The reflectance data displayed in Fig. 7 may seem lower than expected, particularly when compared to those presented elsewhere [29], where significantly higher reflectance values are reported. This fact is explained by the reduced surface area of the specimens used in this study. As the $L$ value regards to the amount of radiation of the light source that is reflected from the samples surface, the reduced area of analysis used in this study $\left(7 \mathrm{~mm}^{2}\right)$ showed to have influence on the amount of reflected light that was measured by the spectrophotometer

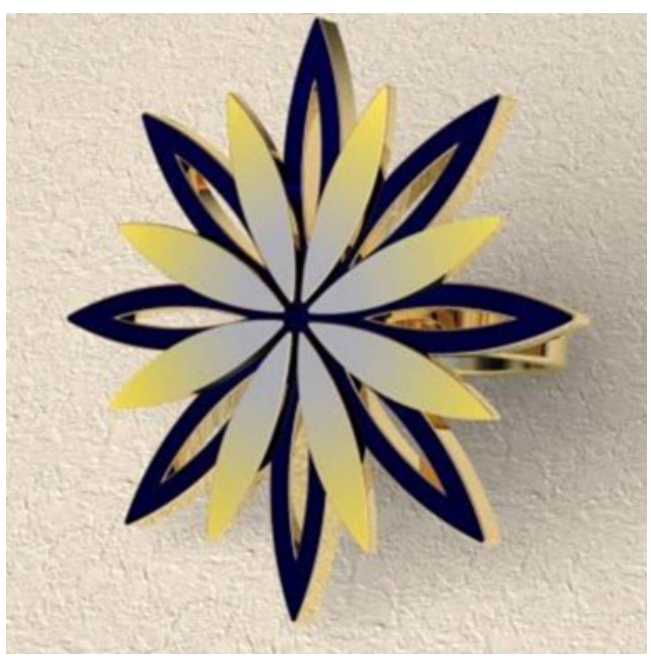

Fig. 9 Multi-coloured gold ring exhibiting parts with colour gradients fabricated by powder metallurgy. Courtesy of Grad'Or Jewels, Portugal (www.gradorjewels.com)

sensor. This fact was confirmed when a higher surface area was tested for a couple of samples and higher $L$ values were obtained. As a consequence of this fact, the analysis of results displayed in Fig. 7 should therefore assume a relative dimension in the comparison of the different gold samples and no definite conclusions about the absolute reflectance values of the specimens should be taken.

\section{Application to the production of jewellery items}

$\mathrm{P} / \mathrm{M}$ can be used as a route for the production of innovative jewellery products, taking advantage of the mixture of powders with different colours to produce patterns with an aesthetic end. Figure 8 shows gold coloured samples produced by the hot pressing powder metallurgy process, using the same gold powders that were studied above. Figure 8 a shows a round part with a bicolour random pattern, yellow and red. This component was obtained by randomly arranging the yellow and red gold powders in a graphite die, followed by hot pressing treatment at $700{ }^{\circ} \mathrm{C}$ during $30 \mathrm{~min}$.

Figure $8 \mathrm{~b}$ shows two parts exhibiting a gradient in colour from one end of the component to the other: from green to white, and from red to white. The transition between the two
Fig. 8 Carat gold components obtained by powder metallurgy: a random pattern in yellow and red colours; b colour gradient between the red-white and green-white, ground surface; c colour gradient between yellow and white, grit-blasted surface
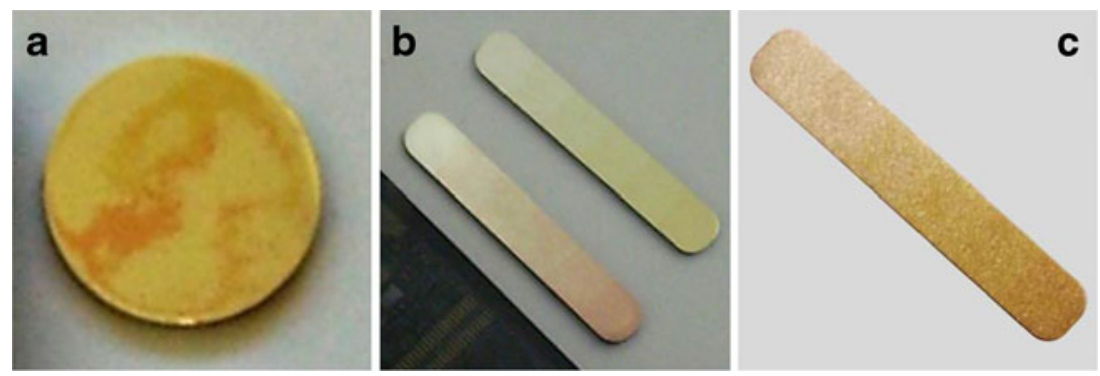
colours in the parts' tips was made in four steps, i.e. four mixtures of the two coloured powders with different volume fractions were used between the two main colours. Powders were hot pressed in a graphite die to final shape at $700{ }^{\circ} \mathrm{C}$ for $30 \mathrm{~min}$. To achieve the appropriate colour contrast, the surface of the part should be in matte finish, which can be also used for masking any surface defect. Parts in Fig. 8b were ground using a 600 -grit $\mathrm{SiC}$ paper. A sandblasting surface treatment can also be applied to the surface of component as shown in Fig. 8c. In this case, the component with colour gradient transition between yellow and white was grit-blasted with $250 \mu \mathrm{m}$ alumina particles.

These are a few examples of how powder metallurgy involving coloured carat gold can be applied to the production of innovative designs for jewellery. Figure 9 shows a jewellery ring where the concept of colours and colour gradients had been applied. It is inspired in a flower where the top petals display a radial continuous colour transition between white and yellow.

\section{Conclusions}

Within the limitations of this study, the following conclusions can be drawn:

1. The different hot pressing conditions did not produce significant changes in microstructure among the tested alloys;

2. The mean porosity measured in the hot pressed samples was lower than $1 \%$;

3. The hardness of the hot pressed samples was not significantly affected by the different processing conditions;

4. The coloured gold alloys showed different coordinates in the CIELab system and the colour of each alloy was not significantly affected by the different hot pressing conditions;

5. The alloys based on the ternary systems $\mathrm{Au}-\mathrm{Ag}-\mathrm{Cu}$ (A, B and C) exhibited similar spectral reflectance curves, whereas that of the alloy D was different, especially for long wavelengths. This behaviour was explained by the presence of nickel in the alloy.

6. The innovation possible in the design of jewellery items through the use of powder metallurgy was demonstrated in this study.

Acknowledgments This work has been supported by post-doc grant of FCT (Portuguese Foundation for Science and Technology) with the reference SFRH/BPD/87435/2012. The authors would like to address special thanks to Doctor Christopher W. Corti and to Engineer Paolo Battaini for their kind advice in this paper.

Open Access This article is distributed under the terms of the Creative Commons Attribution License which permits any use, distribution, and reproduction in any medium, provided the original author(s) and the source are credited.

\section{References}

1. Cretu C, van der Lingen E, Glaner L (2000) Hard 22 carat gold alloy. Gold Technol (No. 29, Summer):p25-28

2. Cretu C, van der Lingen E (1999) Coloured gold alloys. Gold Bull 32(4):115-126

3. Poliero M (2001) White golds for investment casting. Gold Technol (No. 31, Spring):p10-20

4. Fischer-Bühner J, Basso A, Poliero M (2010) Metallurgy and processing of coloured gold intermetallics - part II: investment casting and related alloy design. Gold Bull 43(1):11-20

5. Klotz UE (2010) Metallurgy and processing of coloured gold intermetallics - part I: properties and surface processing. Gold Bull 43(1):4-10

6. Corti CW (2003) Technology is irrelevant to jewellery design-or is it? In: Bell E (ed) Proceedings of the Santa Fe Symposium, pub. Met-Chem Research Inc, Albuquerque, NM, USA. p15-28

7. Böhm W (1998) Design opportunities through production technology. Gold Technol (No. 23, April):p8-11

8. Strauss JT (2003) P/M (powder metallurgy) in jewelry manufacturing; current status, new developments, and future projections. In: Bell E (ed) Proceedings of the Santa Fe Symposium, pub. Met-Chem Research Inc, Albuquerque, NM, USA, p387-412

9. Raw P (2000) Mass production of gold and platinum wedding rings using powder metallurgy. In: Bell E (ed) Proceedings of the Santa Fe Symposium, pub. Met-Chem Research Inc, Albuquerque, NM, USA, p251-270

10. Wiesner K (2003) Metal injection molding (MIM) Technology with 18-ct Gold-A Feasible Study. In: Bell E (ed) Proceedings of the Santa Fe Symposium, pub. Met-Chem Research Inc, Albuquerque, NM, USA, p443-462

11. Strauss JT (1996) Metal injection molding for gold jewelry production. Gold Technol (No. 20, November):p17-29

12. Raw P (1999) Gold wedding rings from powder-tomorrow's technology today. Gold Technol (No. 27, November):p2-8

13. Strauss JT (2004) The potential of MIM for the manufacture of precious metal components. Adv Powder Metall Part Mater

14. Strauss JT (2007) Application of MIM for jewelry manufacturing, presented at PIM2007, Orlando, Florida

15. Raw P (2000) Development of a powder metallurgical technique for the mass production of carat gold wedding rings. Gold Bull 33:79-88

16. Taylor SS (1997) Decorative precious metals composites give a new dimension to jewellery design. In: Bell E (ed) Proceedings of the Santa Fe Symposium, pub. Met-Chem Research Inc, Albuquerque, NM, USA, p443-465

17. Zito D (2001) Coloured carat golds for investment casting. Gold Technol (No. 31, Spring):p35-42

18. Ott D, Raub CJ (1981) Grain size of gold and gold alloys. Gold Bull 14:69-74

19. Ott D, Schindler U (2001) Metallography of gold and gold alloys. Gold Technol (No. 33 Winter):p6-11

20. Henriques B, Soares D, Silva F (2011) Optimization of bond strength between gold alloy and porcelain through a composite interlayer obtained by powder metallurgy. Mater Sci Eng, A 528:1415-1420

21. Henriques B, Soares D, Silva F (2011) Shear bond strength of a hot pressed $\mathrm{Au}-\mathrm{Pd}-\mathrm{Pt}$ alloy-porcelain dental composite. J Mech Behav Biomed Mater 4(8):1718-1726

22. Henriques B, Soares D, Silva F (2012) Microstructure, hardness, corrosion resistance and porcelain shear bond strength comparison between cast and hot pressed CoCrMo alloy for metal-ceramic dental restorations. J Mech Behav Biomed Mater 12:83-92

23. Henriques B, Soares D, Silva F (2012) Experimental evaluation of the bond strength between a CoCrMo dental alloy and porcelain 
through a composite metal-ceramic graded transition interlayer. $\mathrm{J}$ Mech Behav Biomed Mater 13:206-214

24. Henriques B, Soares D, Silva F (2012) Shear bond strength comparison between conventional porcelain fused to metal and new functionally graded dental restorations after thermal-mechanical cycling. J Mech Behav Biomed Mater 13:194-205

25. Henriques B, Soares D, Silva F (2012) Influence of preoxidation cycle on the bond strength of CoCrMo-porcelain dental composites. Mater Sci Eng C 32(8):2374-2380

26. Henriques B, Soares D, Silva F (2013) Hot Pressing effect on the bond strength of a CoCrMoSi alloy to a dental porcelain. Mater Sci Eng C 33(1):557-563
27. Corti CW (2008) The role of hardness in jewellery alloys. In: Bell E (ed) Proceedings of the Santa Fe Symposium, pub. Met-Chem Research Inc, Albuquerque, NM, USA, p103120

28. Grimwade M (2009) Introduction to precious metals. Metallurgy for jewelers and silversmiths, first printing. Brynmorgen

29. Shiraishi T, Takuma Y, Fujita T, Miura E, Hisatsune K (2009) Optical properties and microstructures of $\mathrm{Pd}-$ free $\mathrm{Ag}-\mathrm{Au}-\mathrm{Pt}-\mathrm{Cu}$ dental alloys. J Mater Sci 44:2796-2804

30. Ahmad N, Stokes J, Fox NA, Teng M, Cryan MJ (2012) Ultra-thin metal films for enhanced solar absorption. Nano Energ $1: 777-782$ 